\title{
Meningoencefalite em bovinos causada por herpesvírus bovino-5 no Mato Grosso do Sul e São Paulo ${ }^{1}$
}

\author{
Sandro César Salvador ${ }^{2 *}$, Ricardo A. A. Lemos ${ }^{2}$, Franklin Riet-Correa ${ }^{3}$, Paulo Michel \\ Roehe $^{4}$ e Ana Luiza A. R. Osório ${ }^{2}$
}

\begin{abstract}
Salvador S.C., Lemos R.A.A., Riet-Correa F., Roehe P.M. \& Osório A.L.A.R. 1998. [Meningoencephalitis in cattle caused by bovine herpesvirus-5 in Mato Grosso do Sul and São Paulo.] Meningoencefalite em bovinos causada por herpesvírus bovino-5 no Mato Grosso do Sul e São Paulo. Pesquisa Veterinária Brasileira 18(2):75-82. Depto Medicina Veterinária, Universidade Federal do Mato Grosso do Sul, Cx. Postal 649, Campo Grande, MS 79070-900, Brazil.

Fifteen outbreaks of bovine herpesvirus-type 5 (BHV-5) infection were diagnosed from August 1993 to December 1996. Fourteen outbreaks occurred in the State of Mato Grosso do Sul and one in the State of São Paulo. Cattle 6 to 60 months old were affected. Morbidity reached $0.05 \%$ to $5 \%$ and case fatality rate was nearly $100 \%$. The disease occurred in different municipalities and at different times of the year. Clinical signs were exclusively nervous, and the clinical course varied from 1 to 15 days. The main histologic lesions were meningitis, diffuse encephalitis and necrosis of the cerebral cortex with intranuclear inclusion bodies in astrocytes and neurons. BHV-5 was isolated from 11 out of 12 brains of infected animals inoculated in calf testis cells and MDBK cells. The virus was identified by immunoperoxidase staining with use of monoclonal specific antibodies. Outbreaks of infection by BHV-5 represent $5 \%$ of the total number of bovine cases submitted for diagnosis to the Clinical Hospital of the University of Mato Grosso do Sul. These results indicate the importance of the disease in Mato Grosso do Sul and the need for its differentiation from other diseases which affect the nervous system.
\end{abstract}

INDEX TERMS: Meningoencephalitis, bovine herpesvirus-5, BHV-5, cortical cerebral necrosis, cattle, Mato Grosso do Sul.

RESUMO.- Quinze focos de meningoencefalite por herpesvírus bovino-5 (BHV-5) foram diagnosticados entre agosto de 1993 e dezembro de 1996, sendo 14 provenientes do estado do Mato Grosso do Sul e um do estado de São Paulo. A doença ocorreu em diversos municípios e em diferentes épocas do ano. Foram afetados bovinos de 6 a 60 meses de idade, com uma morbidade de $0,05 \%$ a $5 \%$ e letalidade próxima a $100 \%$.

\footnotetext{
${ }^{1}$ Aceito para publicação em 6 de março de 1998.

2 Departamento de Medicina Veterinária, Universidade Federal do Mato Grosso do Sul, Cx. Postal 649, Campo Grande, MS 79070-900 (*Autor para correspondência).

${ }^{3}$ Departamento de Patologia, Faculdade de Veterinária, Universidade Federal de Pelotas, 96010-900 Pelotas, RS.

${ }^{4}$ Fundação Estadual de Pesquisa Agropecuária (FEPAGRO), Centro de Pesquisa Veterinária Desidério Finamor, Cx. Postal 2076, Porto Alegre, RS 90001970 .
}

Os sinais clínicos foram exclusivamente nervosos e o curso da enfermidade variou de 1 a 15 dias. As principais lesões histológicas detectadas foram meningite e encefalite difusa com malacia do córtex cerebral e presença de corpúsculos de inclusão intranucleares em astrócitos e neurônios. $O$ vírus foi isolado do cérebro de 11 de um total de 12 animais, e sua identidade confirmada por imunoperoxidase, utilizando-se anticorpos monoclonais específicos. Os surtos de encefalite por BHV-5 representam 5\% dos diagnósticos realizados em bovinos pelo Hospital Veterinário da Universidade Federal do Mato Grosso do Sul. Os resultados deste trabalho evidenciam a importância da doença no Mato Grosso do Sul e indicam a necessidade de incluir a encefalite por BHV-5 no diagnóstico diferencial de outras doenças do sistema nervoso de bovinos frequentes no Estado.

TERMOS DE INDEXAÇÃO: Meningoencefalite, herpesvírus bovino-5, BHV-5, polioencefalomalacia, bovinos, Mato Grosso do Sul. 


\section{INTRODUÇÃO}

A encefalite por herpesvírus bovino-5 (BHV-5) carateriza-se por meningoencefalite aguda e é altamente fatal, atingindo principalmente animais jovens (George 1991, Jubb et al. 1993, Magyar et al. 1993).

Surtos de meningoencefalite causados por BHV-5 foram descritos na Austrália (Johnston et al. 1962), EUA (Barenfus et al. 1963, Eugster et al. 1974), Canadá (Beck 1975), Hungria (Bartha et al. 1969), Argentina (Carrillo et al. 1983a,b) e Uruguai (Dias et al. 1982). Embora previamente atribuída ao herpesvírus bovino-1 (BHV-1), a encefalite por BHV-5 vem sendo descrita no Rio Grande do Sul desde 1987 (Méndez et al. 1987), acometendo bezerros de menos de um mês de idade (Weiblen et al. 1989, Riet-Correa et al. 1989), bovinos recémdesmamados (Riet-Correa \& Schild 1995) ou com até 2,5 anos de idade (Vasconcelos et al. 1993, Schild et al. 1994). Não obstante, até o presente, não havia um relato mais detalhado deste tipo de infecção em outros Estados do país.

Este trabalho teve por objetivo a descrição de 14 focos de encefalite causada por BHV-5 em bovinos no Estado do Mato Grosso do Sul e um foco em São Paulo, ocorridos entre agosto de 1993 e dezembro de 1996.

\section{MATERIAL E MÉTODOS}

A história clínica dos casos foi obtida através de entrevistas com proprietários ou médicos veterinários que acompanharam os focos ocorridos entre agosto de 1993 e dezembro de 1996.

Os focos foram identificados por códigos de F1 a F15 e os animais provenientes dos focos, por códigos de caso C1 a C21. Dos 21 casos acompanhados, em 8 as necropsias foram realizadas pelos autores, enquanto em 13 as necropsias foram realizadas por veterinários de campo sendo o encéfalo enviado para o Laboratório de Patologia da Universidade Federal do Mato Grosso do Sul (UFMS). (Quadro 1)

Quadro 1. Identificação dos focos e respectivos casos de encefalite causada por BHV-5 em bovinos no período de agosto de 1993 a dezembro de 1996

\begin{tabular}{clll}
\hline No Foco & N Caso & Tipo de morte & Origem do material \\
\hline F1 & C1 & Sacrificado & Necropsiado na UFMS \\
& C2 & Natural & Necropsiado na UFMS \\
& C3 & Não Informado & Enviado por veterinário \\
& C4 & Não Informado & Enviado por veterinário \\
F2 & C5 & Não Informado & Enviado por veterinário \\
F3 & C6 & Sacrificado & Enviado por veterinário \\
F4 & C7 & Não Informado & Enviado por veterinário \\
F5 & C8 & Não Informado & Enviado por veterinário \\
F6 & C9 & Não Informado & Enviado por veterinário \\
F7 & C10 & Não Informado & Enviado por veterinário \\
F8 & C11 & Não Informado & Enviado por veterinário \\
& C12 & Sacrificado & Necropsiado \\
F9 & C13 & Não Informado & Enviado por veterinário \\
F10 & C14 & Natural & Enviado por veterinário \\
F11 & C15 & Sacrificado & Necropsiado na UFMS \\
& C16 & Sacrificado & Necropsiado na UFMS \\
F12 & C17 & Natural & Necropsiado na UFMS \\
F13 & C18 & Sacrificado & Enviado por veterinário \\
F14 & C19 & Natural & Necropsiado na UFMS \\
& C20 & Sacrificado & Necropsiado na UFMS \\
F15 & C21 & Natural & Enviado por veterinário \\
& & &
\end{tabular}

Para o estudo histológico, órgãos das cavidades abdominal e torácica bem como o encéfalo foram fixados em formalina a $10 \%$, processados em parafina, cortados em seções de $6 \mu$ e corados pela técnica de hematoxilina-eosina. Adicionalmente, em 9 bovinos, foram realizados cortes representativos do sistema nervoso central (SNC) nas seguintes áreas: córtex cerebral na região frontal, parietal e occipital; cápsula interna; tálamo; tubérculo quadrigêmeo rostral; cerebelo; ponte; medula oblonga e medula cervical.

Os critérios histológicos adotados para o estabelecimento do diagnóstico de infecção por BHV-5 foram a presença de: meningite não supurativa; encefalite difusa caraterizada por manguitos perivasculares, constituídos principalmente por linfócitos e macrófagos; corpúsculos de inclusão intra-nucleares em astrócitos e neurônios; polioencefalomalacia caraterizada por necrose neuronal com neurônios eosinofílicos e retraídos, conferindo aparência cribriforme ao córtex cerebral, e/ou acúmulo de macrófagos com citoplasma espumoso (células Gitter). (Carrillo et al. 1983b)

O diagnóstico virológico foi realizado como segue: suspensões de tecido nervoso a $10 \%-20 \%$ em meio mínimo Essencial de Eagle (E-MEM) foram clarificadas, filtradas em filtros $0,22 \mu \mathrm{m}$ e inoculadas em cultivos de células da linhagem "Madin Darby Bovine Kidney" (MDBK) ou em cultivos primários de células de testículos de terneiro (TT). Após a adsorção por uma hora a $37^{\circ} \mathrm{C}$, o inóculo foi removido, os cultivos lavados com E-MEM e um novo volume de meio fresco adicionado. As garrafas contendo as células foram então incubadas novamente a $37^{\circ} \mathrm{C}$ por $5-10$ dias ou até que fosse observado a presença de efeito citopático $(\mathrm{ECP})$. Nos casos em que não foi evidenciado ECP, as células foram submetidas até três subcultivos. As amostras em que o vírus foi detectado foram submetidas a testes subsequentes visando confirmar a identidade do mesmo. Nestes casos, os vírus isolados foram multiplicados em cultivo de células MDBK sobre placas de 96 orifícios e seu perfil de reatividade determinado frente a um painel de 15 anticorpos monoclonais antiherpesvírus bovinos (AcM) submetidos a prova de imunoperoxidase, como descrito anteriormente (Silva et al. 1996, Almeida 1997, Roehe et al. 1997). Todos os materiais foram submetidos a diagnóstico de raiva, segundo métodos usuais (Roehe et al. 1987).

Os animais dos rebanhos onde ocorreram os focos F11 e F14 foram vacinados, por via intramuscular, com vacina contendo o HVB1 inativado. A vacinação foi realizada durante a ocorrência da enfermidade nas propriedades.

\section{RESULTADOS}

Os principais dados epidemiológicos referentes aos focos de infecção por BHV-5 em bovinos, ocorridos no período compreendido entre agosto de 1993 a dezembro de 1996, estão na Quadro 2. Dos 14 focos ocorridos no Estado do Mato Grosso do Sul, 3 foram observados no Município de Rio Brilhante, 2 em Nova Andradina, 2 em Campo Grande, 1 em Miranda, 1 em Paranhos, 1 em Terenos e 1 em Bandeirantes. Nos demais focos não foi confirmado o município de origem. $\mathrm{O}$ foco observado no Estado de São Paulo ocorreu no município de Araçatuba.

Em todos os focos tratavam-se de animais criados extensivamente, exceto no foco F15 em que o rebanho estava em regime de confinamento. As taxas de morbidade e mortalidade estão registradas na Quadro 2. A frequência de meningoencefalite por BHV-5 em relação às outras doenças diagnosticadas no Mato Grosso do Sul foi de 5\%. Foram observados 17 casos em bovinos da raça Nelore, 3 em bovinos da raça Pardo Suíço e 1 em animal mestiço. 
Quadro 2. Dados epidemiológicos dos focos de HVB-5 diagnosticados em bovinos no período de agosto de 1993 a dezembro de 1996

\begin{tabular}{|c|c|c|c|c|c|c|c|}
\hline Caso $^{\mathrm{a}}$ & Mês & $\begin{array}{l}\text { Total de } \\
\text { animais }\end{array}$ & $\begin{array}{c}\text { Doentes } \\
N^{\circ}(\%)\end{array}$ & $\begin{array}{c}\text { Mortos } \\
\mathrm{N}^{\circ}(\%)\end{array}$ & $\begin{array}{l}\text { Idade } \\
\text { (meses) }\end{array}$ & $\begin{array}{c}\text { Evolução } \\
\text { (dias) }\end{array}$ & Observações \\
\hline $\mathrm{C} 1^{1}$ & set./93 & 400 & $26(6,5)$ & $25(6,25)$ & $14-28$ & $3-15$ & $\begin{array}{c}\text { Estabelecimento } \\
\text { com animais } \\
\text { de diversas origens }\end{array}$ \\
\hline $\mathrm{C} 2$ & abr./94 & $\mathrm{NI}^{\mathrm{b}}$ & 1 & 1 & 48 & $\mathrm{NI}$ & \\
\hline $\mathrm{C} 3$ & abr./94 & $\mathrm{NI}$ & $\mathrm{NI}$ & $\mathrm{NI}$ & 48 & $\mathrm{NI}$ & \\
\hline $\mathrm{C} 4$ & jun./94 & $\mathrm{NI}$ & $\mathrm{NI}$ & $\mathrm{NI}$ & 48 & 1 & \\
\hline C5 & mai./94 & $\mathrm{NI}$ & 14 & 14 & 6 & $\mathrm{NI}$ & $\begin{array}{c}\text { O surto teve } \\
\text { duração de } 4 \text { meses }\end{array}$ \\
\hline $\mathrm{C} 6^{2}$ & ago./94 & 2158 & $1(0,46)$ & $1(0,46)$ & 20 & 2 & \\
\hline$C 7^{3}$ & abr./95 & 1100 & $19(1,73)$ & $19(1,73)$ & 24 & $\mathrm{NI}$ & $\begin{array}{c}\text { Sinais respiratórios } \\
30 \text { dias antes } \\
\text { do foco }\end{array}$ \\
\hline $\mathrm{C} 8^{2}$ & jul./95 & 2100 & $5(0,24)$ & $5(0,24)$ & 10 & 6 & \\
\hline C9 & set./95 & $\mathrm{NI}$ & 1 & 1 & 18 & $\mathrm{NI}$ & \\
\hline $\mathrm{C} 10^{1}$ & out./95 & 400 & $1(0,25)$ & $1(0,25)$ & 60 & 8 & $\begin{array}{c}\text { Estabelecimento } \\
\text { com animais } \\
\text { de diversas origens }\end{array}$ \\
\hline $\mathrm{C} 11^{3}$ & nov./95 & 1100 & $2(0,18)$ & $2(0,18)$ & $24-36$ & 2 & \\
\hline C12 & mar./96 & 60 & $1(1,66)$ & $1(1,66)$ & 6 & 4 & \\
\hline C13 & abr./96 & 1300 & $1(0,08)$ & $1(0,08)$ & 6 & 5 & \\
\hline C14 & abr./96 & 800 & $40(5)$ & $40(5)$ & $12-24$ & $5-10$ & \\
\hline $\mathrm{C} 15^{2}$ & set./96 & 2000 & $1(0,05)$ & $1(0,05)$ & 20 & 2 & Confinados a 90 dias \\
\hline
\end{tabular}

a Os casos cujo número é seguido por números elevados iguais ocorreram na mesma propriedade.

b Não informado.

Os sinais clínicos incluíam, inicialmente, depressão e afastamento do rebanho. Estes sinais eram seguidos por acentuada ataxia, hipermetria e andar em círculos, cegueira aparen- te, salivação excessiva, nistagmo, movimentos de propulsão e ocasionais convulsões acompanhadas por decúbito temporário, evoluindo para decúbito lateral permanente e coma.

Quadro 3. Lesões histológicas encontradas nos casos de encefalite causada por HVB-5 em bovinos no período de agosto de 1993 a dezembro de 1996

\begin{tabular}{|c|c|c|c|c|c|c|c|c|c|c|}
\hline Caso & $\begin{array}{l}\text { Isolamento } \\
\text { de vírus }\end{array}$ & $\begin{array}{l}\text { Necrose } \\
\text { neuronal }\end{array}$ & Malacia & Manguitos & Meningite & Corpúsculos & Hemorragias & Neuronofagia & Gliose & Neutrófilos \\
\hline $\mathrm{C} 1$ & Positivo & $+^{\mathrm{b}}$ & +++ & ++ & +++ & + & - & - & - & - \\
\hline $\mathrm{C} 2$ & Positivo & - & +++ & ++ & ++ & + & - & - & - & - \\
\hline $\mathrm{C} 3$ & Positivo & ++ & - & ++ & ++ & - & - & + & + & - \\
\hline $\mathrm{C} 4$ & Positivo & + & + & +++ & + & ++ & - & - & - & - \\
\hline $\mathrm{C} 5$ & $\mathrm{NR}^{*}$ & - & - & ++ & ++ & + & + & - & - & - \\
\hline C6 & NR & + & + & + & ++ & + & - & - & - & - \\
\hline $\mathrm{C} 7$ & NR & + & + & ++ & + & + & + & - & - & - \\
\hline $\mathrm{C} 8$ & NR & + & + & + & + & + & - & - & - & - \\
\hline $\mathrm{C} 9$ & NR & +++ & - & + & + & +++ & - & - & - & - \\
\hline $\mathrm{C} 10$ & Positivo & +++ & - & +++ & +++ & +++ & - & - & - & - \\
\hline C11 & Positivo & + & - & +++ & + & ++ & - & - & + & + \\
\hline C12 & Positivo & +++ & ++ & +++ & +++ & ++ & - & - & +++ & - \\
\hline C13 & NR & +++ & - & ++ & +++ & $?$ & - & - & - & - \\
\hline $\mathrm{C} 14$ & NR & - & +++ & +++ & +++ & $?$ & - & - & - & - \\
\hline C15 & NR & - & ++ & +++ & ++ & ++ & - & - & - & - \\
\hline C16 & NR & + & + & ++ & ++ & +++ & - & ++ & - & - \\
\hline $\mathrm{C} 17$ & Negativo & - & +++ & ++ & +++ & ++ & - & - & - & - \\
\hline C18 & NR & - & ++ & ++ & ++ & + & - & - & - & - \\
\hline C19 & Positivo & - & ++ & +++ & +++ & + & - & - & - & - \\
\hline $\mathrm{C} 20$ & Positivo & +++ & +++ & + & +++ & + & + & - & - & - \\
\hline $\mathrm{C} 21$ & NR & + & + & +++ & + & + & - & - & - & - \\
\hline
\end{tabular}

a NR - não realizado;

b +++ Lesões severas; ++ moderadas; + discretas; - ausentes; ? inconclusivas. 
Quadro 4. Distribuição das lesões histológicas em diferentes regiões do SNC de nove casos de encefalite em bovinos no Mato Grosso do Sul ocorridos de agosto de 1993 a dezembro de 1996

\begin{tabular}{|c|c|c|c|c|c|c|c|c|c|c|c|}
\hline $\begin{array}{c}\text { Caso } \\
\text { (evolução) }\end{array}$ & Lesão & $\begin{array}{l}\text { Córtex } \\
\text { frontal }\end{array}$ & $\begin{array}{l}\text { Córtex } \\
\text { parietal }\end{array}$ & $\begin{array}{l}\text { Córtex } \\
\text { occipital }\end{array}$ & $\begin{array}{l}\text { Cápsula } \\
\text { interna }\end{array}$ & Tálamo & $\begin{array}{c}\text { Tubérculo } \\
\text { quadrigêmio }\end{array}$ & Ponte & Cerebelo & $\begin{array}{l}\text { Medula } \\
\text { oblonga }\end{array}$ & $\begin{array}{l}\text { Medula } \\
\text { cervical }\end{array}$ \\
\hline $\mathrm{C} 1$ & $\mathrm{Me}^{\mathrm{a}}$ & $+++\mathrm{M}$ & $+\mathrm{M}$ & - & - & - & + & - & $+\mathrm{M}$ & $+M$ & - \\
\hline \multirow[t]{4}{*}{$(6 \mathrm{~d})$} & $\mathrm{Mg}$ & ++ & - & - & ++ & +++ & + & + & ++ & ++ & ++ \\
\hline & NN & + & NV & - & NV & - & - & - & - & - & - \\
\hline & Ml & +++ & - & - & - & $+\mathrm{NG}$ & - & - & - & - & - \\
\hline & $\mathrm{Cp}$ & $+(\mathrm{A})$ & - & - & $+(\mathrm{A})$ & $+(\mathrm{A})$ & - & - & - & - & - \\
\hline $\mathrm{C} 2$ & $\mathrm{Me}$ & & ++ & & NC & NC & - & & + & & \\
\hline \multirow[t]{4}{*}{$(4 \mathrm{~d})$} & $\mathrm{Mg}$ & & ++ & & $++\mathrm{M}$ & ++ & ++ & & + & & \\
\hline & NN & NC & +++ & NC & ++ & - & - & NC & - & NC & $\mathrm{NC}$ \\
\hline & Ml & & +++ & & $++\mathrm{F}$ & - & $+(\mathrm{F})$ & & - & & \\
\hline & $\mathrm{Cp}$ & & +++ & & $+(\mathrm{A})$ & - & - & & - & & \\
\hline $\mathrm{C} 9$ & $\mathrm{Me}$ & $++M$ & + & & $\mathrm{NC}$ & & & & + & & \\
\hline \multirow[t]{4}{*}{$(2 \mathrm{~d})$} & $\mathrm{Mg}$ & + & + & & + & & & & + & & \\
\hline & NN & +++ & + & NC & - & $\mathrm{NC}$ & $\mathrm{NC}$ & $\mathrm{NC}$ & - & $\mathrm{NC}$ & $\mathrm{NC}$ \\
\hline & Ml & - & - & & - & & & & - & & \\
\hline & $\mathrm{Cp}$ & +++ & - & & $+(\mathrm{A})$ & & & & - & & \\
\hline C12 & $\mathrm{Me}$ & & $+\mathrm{M}$ & $++M$ & $+++\mathrm{M}$ & NC & & NC & & & \\
\hline \multirow[t]{4}{*}{$(5 \mathrm{~d})$} & $\mathrm{Mg}$ & & $++M$ & ++ & + & + & & $++\mathrm{M}$ & & & \\
\hline & NN & NC & + & +++ & ++ & NV & $\mathrm{NC}$ & - & $\mathrm{NC}$ & $\mathrm{NC}$ & $\mathrm{NC}$ \\
\hline & Ml & & ++ & $+++\mathrm{M}$ & +++ & $+\mathrm{F}$ & & $+F$ & & & \\
\hline & $\mathrm{Cp}$ & & $+\mathrm{NA}$ & + & $+\mathrm{A}$ & $+A$ & & $+A$ & & & \\
\hline $\mathrm{C} 15$ & $\mathrm{Me}$ & + & ++ & + & + & & - & ++ & ++ & + & - \\
\hline \multirow[t]{4}{*}{$(1 \mathrm{~d})$} & $\mathrm{Mg}$ & - & + & - & ++ & & ++ & ++ & +++ & +++ & ++ \\
\hline & NN & - & - & - & - & NC & - & - & - & - & - \\
\hline & Ml & - & - & - & + & & ++ & ++ & ++ & ++ & + \\
\hline & $\mathrm{Cp}$ & - & + & - & - & & - & - & - & - & - \\
\hline C16 & $\mathrm{Me}$ & ++ & + & ++ & + & $++M$ & $++\mathrm{M}$ & - & + & - & \\
\hline \multirow[t]{4}{*}{ (2d) } & $\mathrm{Mg}$ & ++ & ++ & + & + & ++ & ++ & ++ & ++ & - & \\
\hline & NN & + & + & + & + & + & - & NV & - & NV & $\mathrm{NC}$ \\
\hline & Ml & - & - & - & + & + & + & + & - & + & \\
\hline & $\mathrm{Cp}$ & $+\mathrm{N}$ & + & $+B$ & $+\mathrm{N}$ & $+\mathrm{N}$ & + & $?$ & - & $?$ & \\
\hline C17 & $\mathrm{Me}$ & $+++\mathrm{M}$ & ++ & + & $+++\mathrm{M}$ & ++ & ++ & - & ++ & - & - \\
\hline \multirow[t]{4}{*}{$(4 \mathrm{~d})$} & $\mathrm{Mg}$ & $+++\mathrm{M}$ & + & - & + & $++\mathrm{M}$ & ++ & ++ & ++ & - & - \\
\hline & NN & ++ & +++ & +++ & - & - & - & - & - & - & GD \\
\hline & Ml & +++ & - & - & $+\mathrm{F}$ & $+\mathrm{F}$ & $++\mathrm{F}$ & - & ++ & - & - \\
\hline & $\mathrm{Cp}$ & ++ & ++ & + & - & - & - & - & - & - & - \\
\hline \multirow{5}{*}{$\begin{array}{l}\text { C19 } \\
(4 \mathrm{~d})\end{array}$} & $\mathrm{Me}$ & & $+++\mathrm{M}$ & & NC & + & & & & & \\
\hline & $\mathrm{Mg}$ & & $+++\mathrm{M}$ & & +++ & +++ & & & & & \\
\hline & NN & $\mathrm{NC}$ & +++ & $\mathrm{NC}$ & - & - & $\mathrm{NC}$ & $\mathrm{NC}$ & $\mathrm{NC}$ & $\mathrm{NC}$ & $\mathrm{NC}$ \\
\hline & Ml & & +++ & & ++ & $++\mathrm{F}$ & & & & & \\
\hline & $\mathrm{Cp}$ & & + & & - & - & & & & & \\
\hline \multirow{5}{*}{$\begin{array}{c}\mathrm{C} 20 \\
(10 \mathrm{~d})\end{array}$} & $\mathrm{Me}$ & +++ & ++ & $+++\mathrm{M}$ & ++ & $\mathrm{NC}$ & & NC & ++ & + & - \\
\hline & $\mathrm{Mg}$ & + & ++ & ++ & ++ & ++ & & + & + & + & ++ \\
\hline & NN & +++ & ++ & +++ & ++ & + & $\mathrm{NC}$ & - & - & - & NV \\
\hline & Ml & ++ & - & +++ & $+\mathrm{F}$ & - & & + & + & - & $+\mathrm{F}$ \\
\hline & $\mathrm{Cp}$ & ++ & $+\mathrm{N}$ & + & + & - & & - & - & - & - \\
\hline
\end{tabular}

aA - astrócitos; Cp -corpúsculos de inclusão; F - focal; M - infiltrado inflamatório composto predominantemente de macrófagos; Me - meningite; Mg manguitos perivasculares; $\mathrm{Ml}$-malacia; $\mathrm{N}$ - neurônios; $\mathrm{NC}$ - não consta; $\mathrm{NN}$ - necrose neuronal.

Em 15 bovinos o curso clínico variou de 1 a 6 dias, em um foi de 8 dias e em outro de 15 dias; em 4 casos não foi determinado o tempo de evolução.

A ausência de alterações significativas à necropsia foi relatada com frequência pelos veterinários a campo. Em grande parte dos cérebros examinados não foram observadas alterações significativas ( 9 casos), ou apresentaram achados inespecíficos, como congestão (7 casos). Seis animais apresentaram áreas de malacia caraterizadas por áreas deprimidas, de 1 a $2 \mathrm{~cm}$ de diâmetro, de coloração amarelada ou avermelhada no córtex cerebral. Outras lesões observadas nesses casos foram achatamento das circunvoluções (4 casos), protusão do cerebelo pelo foramen magno (4 casos) e pontos hemorrágicos no córtex cerebral (2 casos).

As alterações histológicas dos 21 casos necropsiados provenientes dos 12 focos diagnosticados encontram-se no Quadro 3. Os resultados do mapeamento das lesões histológicas no encéfalo e na medula cervical dos bovinos necropsiados, realizado em 9 casos provenientes de 6 focos da doença, estão apresentados no Quadro 4.

As principais alterações histológicas encontradas no SNC foram meningite não supurativa difusa severa, associada a 
uma encefalite também difusa e caracterizada pela presença de manguitos perivasculares de células mononucleares, localizada tanto na substância branca como na cinzenta, sendo mais espessos na primeira, onde eram formados por até 16 camadas de células inflamatórias. Os manguitos encontrados nas áreas de malacia do córtex eram tão espessos quanto na substância branca. No cerebelo apenas a substância branca foi afetada, não encontrando-se alterações no córtex. $O$ infiltrado inflamatório meningeano e perivascular era composto principalmente por linfócitos e macrófagos, sendo que nas áreas de malacia, predominavam os macrófagos. Ocasionalmente, encontravam-se neutrófilos organizados concentricamente em pequenos nódulos e áreas hemorrágicas.

Necrose neuronal maciça, atingindo grandes extensões do córtex, não apresentando padrão laminar, mas envolvendo todas as camadas corticais, foi um achado consistentemente encontrado, conforme verifica-se no Quadro 3. Estas áreas foram caracterizadas pela presença de neurônios acentuadamente eosinofílicos, retraídos, com aumento do espaço perineuronal. Observavam-se, ocasionalmente, neuronofagia, gliose multifocal ou difusa e infiltrado inflamatório mononuclear difuso na neurópila, constituído principalmente por macrófagos. Nessas áreas constatou-se a presença de grande número de corpúsculos de inclusão intranucleares eosinofílicos, sendo observados mais frequentemente do que em qualquer outra área dos casos do presente estudo.

Observou-se malacia (com presença de macrófagos de citoplasma espumoso) nos casos onde a evolução foi igual ou superior a 3 dias. No córtex a principal localização das células Gitter foi na camada mais superficial ou região submeningeana. Ocasionalmente encontravam-se áreas descorticadas, com substituição da neurópila por células Gitter e as meninges repousando sobre os vasos sanguíneos. Já na cápsula interna, tálamo, tubérculo quadrigêmeo, ponte, cerebelo, medula oblonga e medula cervical a malacia era caracterizada por múltiplos nódulos gliais nos casos menos avançados e por acúmulos focais de macrófagos nos casos com lesões mais severas (Quadro 4).

Corpúsculos de inclusão intranucleares foram observados em astrócitos e neurônios, em 18 dos 21 casos, sendo mais frequentes nos astrócitos. Estes corpúsculos eram na sua maioria eosinofílicos e apresentavam-se ao centro do núcleo com um alo claro em volta e a cromatina rebatida perifericamente. Ocasionalmente, foram encontrados corpúsculos basofílicos que ocupavam todo o núcleo que mostrava-se de tamanho aumentado. Em dois casos, nos quais não foram observados corpúsculos de inclusão, o material encontravase autolisado.

Nos 21 animais necropsiados não foram constatadas alterações em outros órgãos, exceto no caso número 17 , onde o pulmão apresentou espessamento difuso do epitélio alveolar, congestão, edema, presença de material vegetal na luz bronquiolar e sem a observação de lesões compatíveis com pneumonia de origem viral.

Nos cultivos celulares inoculados com material coletado de 11 dos 12 casos, provenientes de 6 focos, constatou-se efeito citopático caraterístico dos herpesvírus. BHV-5 foi iden- tificado pela prova de imunoperoxidase frente a anticorpos monoclonais específicos nos casos C1, C2, C3, C4, C10, C11, C12, C15, C16, C19 e C20, provenientes dos focos F1, F7, F8, $\mathrm{F} 11$, F14. No material de $\mathrm{C} 17$ o vírus não foi isolado.

Nos estabelecimentos onde ocorreram os focos F11 e F14 não foram observados mais casos clínicos da doença após a vacinação. Na propriedade onde ocorreu o foco F12, os animais eram regularmente vacinados a partir dos 12 meses de idade, sendo que o único caso registrado afetou um animal de 6 meses.

\section{DISCUSSÃO}

Todos os animais estudados apresentaram achados histológicos característicos de infecção por BHV-5, evidenciados por meningoencefalite difusa, não supurativa, associada a necrose do córtex cerebral e, exceto em 3 casos, à presença de corpúsculos de inclusão intranucleares eosinofílicos ou basofílicos em astrócitos e neurônios (Bagust \& Clark 1972, Hill et al. 1984).

A confirmação do diagnóstico através do isolamento viral e identificação do BHV-5 através de AcM específicos, foi realizada em 11 animais provenientes de 5 focos. $O$ resultado negativo da tentativa de isolamento viral no caso $\mathrm{C} 17$ deveuse, provavelmente, ao armazenamento do material a $-20^{\circ} \mathrm{C}$, condição na qual o BHV-5 perde rapidamente a infectividade.

Em 18 dos 21 casos estudados foram observadas inclusões intranucleares em neurônios e astrócitos. Esta observação sugere que a presença de inclusões intranucleares nestas células é frequente, diferindo do mencionado por George (1991) que considera tal achado raro. Em dois dos casos onde a caracterização definitiva dos corpúsculos não foi possível, o material apresentava-se autolisado. Summers et al. (1995) descrevem a observação de corpúsculos de inclusão apenas em materiais bem preservados. A observação ocasional de corpúsculos de basofílicos pode ser atribuída à fase inicial de replicação viral, observando-se eosinofilia numa fase tardia do ciclo viral (Fenner et al. 1993).

A enfermidade não apresentou caráter sazonal, sendo diagnosticada na maioria dos meses do ano. Os meses de abril e setembro registram o maior número de focos. Igualmente, na literatura consultada não se encontrou associação entre número de surtos e época do ano.

A idade dos animais atingidos variou entre os 6 e 60 meses, sendo que o maior número de casos ocorreu entre os 13 e 18 meses de idade. Vasconcelos et al. (1993) e Beck (1975) descrevem surtos de encefalite em bovinos com idade entre 2 e 3 anos. No Rio Grande do Sul a maioria dos surtos ocorre entre os 6 meses e 2 anos de idade (Riet Correa et al. 1996) ou em bovinos lactentes (Riet-Correa et al. 1989, Weiblen et al. 1989). Em outros surtos relatados a idade dos animais doentes foi igual ou inferior a 6 meses (Johnston et al. 1962, French 1962, Barenfus et al. 1963, Bartha et al. 1969).

A distribuição geográfica dos casos no Mato Grosso do Sul revela que a maioria deles ocorreu num raio aproximado de $300 \mathrm{~km}$ de Campo Grande, exceto o foco no município de Paranhos, significativamente mais distante. Estudos comple- 
mentares seriam necessários para afirmar se tal fato se deve à maior prevalência do BHV-5 na região próxima a Campo Grande ou ao maior alcance do Laboratório nessa área.

A morbidade e mortalidade apresentaram grande variação $(0,05 \%$ a $5 \%)$, caracterizando a ocorrência da enfermidade tanto na forma de surtos como na forma de casos isolados. Em outros relatos da doença a morbidade variou de $15 \%$ a 50\% (Johnston et al. 1962, Carrillo et al. 1983a, Hill et al. 1984). Nos focos tratavam-se, em sua maioria, de casos isolados da doença, sem o acometimento de grande número de animais ao mesmo tempo. Por outro lado, em 3 propriedades, no mesmo rebanho, foram diagnosticados 2 ou 3 focos da doença, em épocas e anos diferentes (Quadro 2). As taxas de mortalidade foram semelhantes às de morbidade, uma vez que a letalidade foi virtualmente de $100 \%$, com apenas um animal clinicamente afetado recuperando-se. Na literatura são descritas taxas de letalidade próximas a $100 \%$, com a recuperação ocasional de poucos animais que apresentaram sinais clínicos (Carrillo et al. 1983a, Johnston et al. 1962), embora outros autores tenham encontrado letalidade de 75\% (RietCorrea et al. 1989).

De todos os focos diagnosticados apenas um ocorreu em rebanho bovino confinado e em apenas um rebanho ocorria compra regular de animais de outras propriedades. Em todos os outros rebanhos as condições de criação eram extensivas. No Rio Grande do Sul os focos ocorrem também em animais em pastejo (Méndez et al. 1987, Riet-Correa et al. 1989, Riet-Correa et al. 1995). No entanto, em surtos descritos em outros países a doença é mais comum em rebanhos de criação semi-intensiva ou intensiva e nos quais ocorre aglomeração de animais de diversas origens (George 1991). Cumpre salientar que na única propriedade onde diagnosticou-se um foco em bovinos confinados, afetando somente um animal, a doença tinha ocorrido anteriormente em duas ocasiões em animais em pastejo (Quadro 2), sem afetar os animais confinados.

A análise epidemiológica encontra-se prejudicada pela falta de informações mais detalhadas, principalmente naqueles focos onde o material foi remetido por veterinários de campo. $O$ sistema de criação extensivo, predominantemente adotado no Estado, com grande número de animais em extensas áreas de pastejo, associada a longas distancias das propriedades até os centros de diagnóstico, dificultam o acompanhamento dos surtos durante sua ocorrência e posterior constatação de novos casos da enfermidade. Desta forma é possível que os dados de morbidade, mortalidade e letalidade não sejam exatos, uma vez que na maioria dos casos as informações enviadas eram referentes apenas ao momento da remessa do material ao laboratório, sem posterior acompanhamento.

Sinais clínicos como ranger dos dentes, corrimento nasal seroso discreto e paralisia da língua foram observados com frequência nos casos acompanhados pelos autores, que também observaram agressividade em 2 casos. Estes sinais foram raramente citados pelos veterinários de campo. Isto acontece, possivelmente, pela maior dificuldade de observação dos sinais clínicos, principalmente em propriedades com gran- des extensões de terra, onde a observação detalhada dos animais torna-se impraticável.

A duração do quadro clínico variou de 1 a 15 dias, com evolução da maioria dos casos ocorrendo entre 1 e 6 dias. Johnston et al. (1962) encontraram evolução média de 6 dias, embora casos com evolução aguda, de 2 a 3 dias, também sejam relatados (Gardiner \& Nairn 1964). Em um surto um animal morreu após apresentar-se clinicamente afetado durante um período de 15 dias. Na literatura consultada a evolução mais longa foi de 7 dias (Riet-Correa et al. 1989). No presente trabalho muitos animais foram sacrificados na fase terminal da doença (Quadro 1), ou em uma fase onde não se tinha informações precisas sobre o estado clínico do animal porque o material foi remetido ao laboratório sem ficha clínica completa. Este fato deve ser levado em consideração na análise dos dados referentes à evolução, principalmente em 3 casos com evolução de apenas 1 dia, que não encontra paralelo na literatura (Johnston et al. 1962, Gardiner \& Nairn 1964, Carrillo et al. 1983a, Hill et al. 1984, Riet-Correa et al. 1989).

Os achados de necropsia no SNC estão de acordo com outros relatos da doença (Johnston et al. 1962, Carrillo et al. 1983b, Hill et al. 1984, Riet-Correa et al. 1989). Em grande parte dos casos não foram observadas alterações significativas, ou apresentaram achados inespecíficos. A ausência de lesões significativas ou presença de lesões inespecíficas são descritas por diversos autores (Beck 1975, Hill et al. 1984). Lesões mais significativas como áreas de malacia, achatamento das circunvoluções, protusão do cerebelo pelo foramen magno e pontos hemorrágicos no córtex cerebral, observados em alguns animais, foram também descritos por outros autores (Gardiner \& Nairn 1964, Riet-Correa et al. 1996).

Todos os achados histológicos característicos de encefalite por BHV-5, descritos anteriormente por outros autores (Johnston et al. 1962, Gardiner \& Nairn 1964, Hall et al. 1966, Dias et al. 1982, Weiblen et al. 1989, JUBB et al. 1993), foram observados nos casos do presente estudo, entretanto a intensidade e distribuição das lesões foram ocasionalmente diferentes (Quadro 4). Alguns desses achados merecem ser comentados com mais detalhes.

Necrose neuronal não associada à presença de células Gitter foi observada em 4 casos que apresentaram evolução inferior a 3 dias. Em outros casos com evolução igual ou superior a 3 dias, a necrose neuronal estava associada a áreas de malacia com presença de macrófagos (Quadro 3). Este fato sugere que a presença de áreas de malacia com macrófagos e a intensidade desta lesão está diretamente relacionada com a duração da evolução clínica. Em processos isquêmicos do SNC as primeiras células Gitter aparecem depois de 48 horas da injúria do tecido nervoso (Carlton \& McGavin 1995).

Com relação à localização das células Gitter, predominantemente na camada mais superficial do córtex, outros autores constataram localização semelhante (Baugust \& Clark 1972). No presente estudo observou-se, também, em casos com malacia mais discreta, a presença de múltiplos nódulos microgliais, principalmente localizados na cápsula interna e tronco encefálico, sendo que ocasionalmente estes nódulos 
encontravam-se associados a células Gitter. Estes achados sugerem que o padrão de distribuição da malacia no córtex é predominantemente sub-meningeano ou na camada mais superficial do mesmo, enquanto que no tronco encefálico este padrão de distribuição é multifocal.

Os manguitos perivasculares eram compostos por várias camadas de células (entre 1 e 16 células), havendo predominância na maioria dos casos de linfócitos, com exceção das áreas adjacentes as áreas de malacia, onde a principal figura celular eram macrófagos. Os manguitos observados na substância branca eram mais espessos e em maior número do que no córtex, exceção feita novamente nas áreas de malacia, onde eram igualmente espessos e numerosos. Johnston et al. (1962) descrevem distribuição similar dessas lesões.

Não foram observadas alterações macro ou microscópicas em outros órgãos, exceto no caso número 17 , onde o pulmão apresentou lesões, provavelmente de uma pneumonia aspirativa. Esta lesão pode ocorrer como consequência de desordens neurológicas (Smith 1996).

Nos 9 casos, provenientes de 6 focos da doença, nos quais foi estudada a distribuição das lesões histológicas no encéfalo e medula cervical, observaram-se variações entre os casos quanto a localização e intensidade dessas lesões (Quadro 4). A maioria dos casos apresentou distribuição similar à encontrada na literatura (Johnston et al. 1962), com lesões inflamatórias e degenerativas, estas últimas incluindo necrose neuronal e malacia, mais severas no córtex cerebral e, menos marcadas, na cápsula interna e tronco encefálico. Entretanto, nos casos 2, 12 e 20 as lesões da cápsula interna eram tão intensas quanto as do córtex. No caso número 16 as lesões inflamatórias e degenerativas foram observadas com severidade semelhante desde o córtex até a ponte. Já o caso 15 apresentou distribuição diferenciada, com infiltrado inflamatório discreto e ausência de alterações degenerativas no córtex, sendo que os segmentos mais severamente atingidos foram o tubérculo quadrigêmeo, ponte, cerebelo e medula oblonga, onde observaram-se malacia e lesões inflamatórias graves. Nestes dois últimos casos, um fato que chamou a atenção foi o tempo de evolução, de 2 dias e de 1 dia, respectivamente, sendo ambos animais sacrificados ainda em estado geral considerado regular, diferente dos demais casos onde a evolução foi superior a 3 dias e a morte, quando não natural, pelo menos ocorria quando o animal estava em estado agônico. Esses fatos sugerem que, inicialmente, as lesões podem ocorrer mais gravemente no tronco encefálico, evoluindo posteriormente para a região cortical. Estas conclusões estariam de acordo com Bagust \& Clark (1972), que encontraram o vírus em níveis detectáveis apenas na região do tronco encefálico com 6 dias decorridos da inoculação experimental, e no tronco encefálico e córtex no $8^{\circ}$ dia, sendo difusa a infeção viral a partir do $11^{\circ}$ dia após a inoculação.

Cabe salientar que a infecção por BHV-5 não foi diagnosticada anteriormente no Mato Grosso do Sul. Considerando-se que muitos dos casos estudados neste trabalho foram remetidos ao laboratório com a suspeita de polioencefalomalacia, é provável que casos anteriores de encefalite por BHV-5 tenham sido confundidos com esta últi- ma. Erros de diagnóstico clínico e histológico entre essas duas doenças tem sido reportadas em outros países (Carrillo et al. 1983b, George 1991). A distribuição da necrose neuronal, envolvendo todas as camadas corticais, mostra-se diferente daquela necrose laminar profunda ou intermediária tradicionalmente reconhecida na polioencefalomalacia. Outra diferença marcante é a presença de corpúsculos de inclusão intranucleares, reconhecidos no presente estudo como localizados principalmente nas áreas de necrose neuronal. 0 infiltrado de células Gitter na camada mais superficial do córtex também apresentou-se mais intenso do que usualmente se observa em casos de polioencefalomalacia. A possibilidade de dificuldade de diagnóstico entre estas enfermidades também foi constatada no caso 16 deste estudo, com lesões inflamatórias discretas e necrose neuronal como principal alteração histológica no córtex cerebral. Isto reforça a necessidade de exame microscópico detalhado de todos os segmentos do encéfalo e, se possível, de todo o SNC. Considerando que a polioencefalomalacia é frequente no Mato Grosso do Sul (Nakazato et al. 1997), é importante o seu diagnóstico diferencial com a infecção por BHV-5. Outras doenças do sistema nervoso dos bovinos que ocorrem nesse Estado, incluindo o botulismo, a raiva e a intoxicação hídrica (Lemos et al. 1997), devem ser diferenciadas da encefalite por BHV-5. 0 botulismo não apresenta lesões histológicas significativas no SNC e a toxina pode ser identificada no soro sanguineo, fígado e trato gastrintestinal. A raiva apresenta encefalite e mielite linfocitária focal a difusa, preferencialmente no tronco encefálico e medula, e presença de corpúsculos de Negri; o vírus pode ser identificado por imunofluorescência e inoculação em camundongos. A intoxicação hídrica caraterizase por meningoencefalite eosinofílica. Lesões de polioencefalomalacia não ocorrem em nenhuma dessas 3 doenças.

Não foram observados mais casos clínicos da doença nas propriedades nas quais os animais foram vacinados com vacinas inativas contendo BHV-1. Na propriedade onde ocorreu o foco F12 os animais eram regularmente vacinados a partir dos 12 meses de idade, sendo que o único caso registrado afetou um animal de 6 meses, período no qual existe perda da imunidade colostral (George 1991). Esses fatos, e a ocorrência da doença em mais de uma ocasião em 3 propriedades, sugerem a eficiência da vacina no controle da mesma. No entanto, não podemos afirmar que o controle da enfermidade tenha ocorrido pelo uso da vacina, já que, em 8 propriedades não realizou-se vacinação e o problema não voltou a ser informado. A imunidade cruzada entre BHV-1 e BHV-5 é relatada em estudos de campo e experimentais (George 1991, Belknap et al. 1994), e a aplicação de vacinas durante a ocorrência de surtos da enfermidade é preconizada visando minimizar ou impedir as manifestações clínicas.

Os casos de infecção por BHV-5 diagnosticados na UFMS entre agosto de 1993 e dezembro de 1995 representaram 5\% de todos os diagnósticos realizados. Estes dados sugerem que esta doença é relativamente frequente no estado, devendo ser considerada, portanto, como economicamente importante.

Agradecimentos.- A Júlio César de Almeida Rosa, responsável pelo isolamento 
viral; Tamir Calcagnotto da Silva e Renata Servan de Almeida, responsáveis pela caracterização através de anticorpos monoclonais BHV-1 e BHV-5, respectivamente; todos pesquisadores do laboratório de virologia da Fundação Estadual de Pesquisa Agropecuária, Rio Grande do Sul.

\section{REFERÊNCIAS}

Almeida R.S. 1997. Produção e caracterização de anticorpos monoclonais contra Herpesvírus da encefalite bovina (BHV-5).Tese de mestrado, Faculdade de Veterinária, Universidade Federal do Rio Grande do Sul.

Bagust T.J. \& Clark L. 1972. Pathogenesis of meningoencephalitis produced in calves by infectious bovine rhinotracheitis herpesvirus. J. Comp. Pathol. 82:375-382.

Barenfus M., Delli Quadri C.A., McIntyre R.W. \& Schroeder R.J. 1963. Isolation of infectious bovine rhinotracheitis virus from calves with meningoencephalitis. J. Am. Vet. Med. Assoc. 143:725-755.

Bartha A., Hadjdu G., Aldasy P. \& Paczolay G. 1969. Occurrence of encephalitis caused by infectious bovine rhinotracheitis virus in calves in Hungary. Acta Vet. Hungaricae 19:145-151.

Beck B.E. 1975. Infectious Bovine Rhinotracheitis in cattle and its differential diagnosis. Canad. Vet. J. 16:269-271.

Belknap E.B., Collins J.K., Ayers V.K. \& Schultheiss P.C. 1994. Experimental infection of neonatal calves with neurovirulent bovine herpesvirus type 1.3. Vet. Pathol. 31:358-365.

Carlton W.W. \& McGavin M.D. 1995. Thomson's Special Veterinary Pathology. 2nd ed. Mosby, St. Louis. 654 p.

Carrillo B.J., Ambrogi A., Schudel A.A., Vazquez M., Dahm E. \& Pospichil A. 1983a. Meningoencephalitis caused by IBR virus in calves in Argentina. Zentralbl. Veterinärmed., Reihe B, 30:327-332.

Carrillo B.J., Pospichil A. \& Dahme E. 1983b. Pathology of a bovine necrotizing encephalitis in Argentina. Zentralbl. Veterinärmed., Reihe B, 30:161-168.

Dias L.E., Maisonave J., Guarino H., Paullier C., Perdomo E., Figares A. \& Izaguirre R. 1982. Rinotraqueitis infecciosa bovina (IBR). Descripción de um cuadro clínico en terneros de tambo. III Congresso Nacional de Veterinaria, Uruguai, p. 521-531.

Eugster A.K., Angulo A.A. \& Jones L.P. 1974. Herpesvirus encephalitis in range calves. Proc. Annu. Meet. Am. Assoc. Vet. Lab. Diagn. 17:267-290.

Fenner FJ., Gibbs E.P., Murphy F.A., Rott R., Studdert M. J. \& White D. 1993. Veterinary Virology. 2nd ed. Academic Press, New York. 659 p.

French E.L.A. 1962. A specific vírus encephalithis in calves: isolation and characterization of the causal agent. Aust. Vet. J. 38:216-221.

Gardiner M.R. \& Nairn, M.E. 1964. Meningoencephalitis of calves in Western Australia. Aust. Vet. J. 40:225-228.

George L.W. 1991. Understanding the encephalitic form of infectious bovine rhinotracheitis. Food Animal Practice, March: 335-337.

Hall W.T.K., Simmons G.C., French E.L., Snowdon W.A. \& Asdell M. 1966. The pathogenesis of encephalitis caused by the infectious bovine rhinotracheitis virus. Aust. Vet. J. 42:229-237.

Hill B.D., Hill M.W.M., Chung Y.S. \& Whittle R.J. 1984. Meningoencephalitis in calves due to bovine herpesvirus type 1 infection. Aust. Vet. J. 61:242-243.
Johnston L.A.Y., Simmons G.C. \& McGavin M.D. 1962. A viral meningoencephalitis in calves. Aust. Vet. J. 38:207-215.

Jubb K.V.F., Kennedy P.C. \& Palmer N. 1993. Pathology of Domestic Animals. Vol. 1. 4th ed. Academic Press, San Diego. 956 p.

Kahrs R.F. 1977. Infectious Bovine Rhinotracheitis: a review and update. J. Am. Vet. Med. Assoc. 171:1055-1064.

Lemos R.A.A., Nakazato L., Barros C.S.L., Gattass C.B.A. \& Bonila R. 1997. Meningoencefalite eosinofílica em bovinos no estado de Mato Grosso do Sul. Anais 10 Reunião Anual do Instituto Biológico, São Paulo, SP, p. 43.

Magyar G., Tanyi J., Hornyak A.E. \& Bartha A. 1993. Restriction endonuclease analysis of hungarian bovine herpesvirus isolates from different clinical forms of IBR, IPV and encephalitis. Acta Vet. Hungaricae 41:159-170.

Méndez M.C., Riet-Correa F., Schild A.L. \& Ferreira J.L.M. 1987. Laboratório Regional de Diagnóstico. Doenças diagnosticadas no ano de 1986. Editora da Universidade, Pelotas. $30 \mathrm{p}$.

Nakazato L., Lemos R.A.A. \& Salvador S.C. 1997. Polioencefalomalacia (PEM) em bovinos no Mato Grosso do Sul. Anais VII Encontro Nacional de Patologia Veterinária, Pirassununga, SP, p. PA-60.

Riet-Correa F., Moojen V., Roehe P. \& Weiblen, R. 1996. Viroses confundíveis com febre aftosa: revisão. Ciência Rural, Santa Maria, 26:323-332.

Riet-Correa F. \& Schild A.L. 1995. Doenças diagnosticadas pelo Laboratório Regional de Diagnóstico no ano de 1994 e comentários sobre algumas doenças. Bolm Lab. Reg. Diagnóstico, Pelotas, 15:7-19.

Riet-Correa F., Vidor T., Schild A.L. \& Méndez M.C. 1989. Meningoencefalite e necrose do córtex cerebral em bovinos causada por herpesvirus bovino-1. Pesq. Vet. Bras. 9:13-16.

Roehe P.M., Rodrigues R.S., Gonçalves A.R. \& Ribeiro C.L.G. 1986. Diagnóstico laboratorial da raiva no Rio Grande do Sul. Boln Oficina Sanitaria Panamericana 120(5):464-475.

Roehe P.M., Silva T.G., Nardi N.B., Oliveira L.G. \& Rosa J.C.A. 1997. Diferenciação entre os vírus da rinotraqueíte bovina infecciosa (BHV-1) e herpesvírus da encefalite bovina (BHV-5) com anticorpos monoclonais. Pesq. Vet. Bras. 17(1):41-44.

Schild A.L., Riet-Correa F., Ferreira J.L.M. \& Méndez, M.C. 1994. Doenças diagnosticadas pelo Laboratório Regional de Diagnóstico em 1993. Bolm Lab. Reg. Diagnóstico, Pelotas, 14:23-26.

Silva T.C., Roehe P.M., Nardi N.B. \& Oliveira L.G. 1996. Produção e caraterização de anticorpos monoclonais contra o vírus da rinotraqueíte infecciosa bovina (BHV-1) Arq. Bras. Med. Vet. Zoot. (Submetido)

Smith B.P. 1996. Large Animal Internal Medicine. 2nd ed. Mosby, London. 1457 p.

Summers B.A., Cummings J.F. \& LaHunta A. 1995. Veterinary Neuropathology. Mosby, London.

Vasconcelos R.O., Varaschin N.S., Wouters F., Nobre V.M.T. \& Barth A.T. 1993. Meningoencefalite Bovina por Herpesvírus. Anais VI Encontro Nacional de Patologia Veterinária, Santa Maria. 64 p.

Weiblen R., Barros C.S.L. \& Canabarro T.F. 1989. Bovine meningoencefalitis from IBR virus. Vet. Rec. 124:666-667. 